\title{
Simulation of ultrasonic vibration in a liquid aluminum bath for sapphire surface modification
}

\author{
Wei Cui ${ }^{1}$, Longfei Chen ${ }^{2}$, Yudong $\mathrm{Zhou}^{3}$, Shuqi $\mathrm{Li}^{4}$ \\ ${ }^{1,2,3}$ College of Electrical and Mechanical Engineering, Hohai University, \\ Changzhou, 213022, People's Republic of China \\ ${ }^{4}$ Changzhou Vocational Institute of Technology, Changzhou, 213164, People's Republic of China \\ ${ }^{1}$ Corresponding author \\ E-mail: 1'cuiwei_academic@163.com,2906418738@qq.com,32859705824@qq.com, \\ ${ }^{4}$ shuqi0211@126.com
}

Received 3 October 2018; accepted 8 October 2018 DOI https://doi.org/10.21595/vp.2018.20300

Check for updates

Copyright (C) 2018 Wei Cui, et al. This is an open access article distributed under the Creative Commons Attribution License, which permits unrestricted use, distribution, and reproduction in any medium, provided the original work is properly cited.

\begin{abstract}
Ultrasonic vibration has been found to play a significant role in promoting surface nano-crystallization of sapphire in a liquid aluminum bath. And the distribution of the vibration field is critical in controlling the modification procedure. Here, distribution of the ultrasonic vibration in a liquid aluminum bath was investigated by finite element method (FEM). Effects of shape of the ultrasonic horn and distance between the horn and the sapphire plates were investigated. It was found that the ultrasonic vibration density is high in the area adjacent to the ultrasonic horn. The distance between the horn and the plates significantly influence the vibration distribution. And the vibration density decreased significantly at the liquid/solid interface, indicating obvious energy absorption there. Vibration energy grads can be formed on sapphire surface. And this phenomenon shall be used to achieve different aims.
\end{abstract}

Keywords: ultrasonic vibration, finite element method, liquid aluminum, sapphire, surface modification.

\section{Introduction}

Monocrystalline $\alpha-\mathrm{Al}_{2} \mathrm{O}_{3}$ is usually named as sapphire. It has many good properties, for example, high strength, significant corrosion resistance and excellent light transmittance. Soldering of sapphire is highly desired in many industries to fabricate devices [1-4]. Soldering process basically involves melting a metal as a "glue" to stick the base materials together. But wetting and bonding between metals and sapphire are poor due to the significant difference in physical and chemical natures between them.

Ultrasound was found to be very effective to promote wetting and bonding in the typical soldering process. Kolenak et al soldered $\mathrm{Al}_{2} \mathrm{O}_{3}$ ceramics with a $\mathrm{Sn}-\mathrm{Ag}-\mathrm{Ti}$ alloy with an ultrasonic soldering method $[5,6]$. In our previous works, ultrasound has been used to build nano-crystalline layers in aluminum melt alloys, which can significantly benefit the wetting and bonding between the sapphire and liquid alloys [7,8].

One key procedure in the ultrasonic treatment of sapphire is the ultrasonic dipping, in which ultrasonic vibration distribution is the essential issue. The locations with higher vibration density are expected to be treated more effectively. Thus, it is very important to know the vibration density field, so that fine control of the procedure can be achieved. However, since it is very difficult to directly measure the ultrasonic vibration distribution, knowledge in this aspect is still far from abundant.

In this study, finite element method (FEM) was used to identify the characteristics of ultrasonic vibration in a liquid aluminum bath. Distribution of the vibration density was investigated in three conditions. This can provide useful reference for ultrasonic vibration-assisted materials treatment. 


\section{Models and methods}

The simulation was carried out by using COMSOL Multiphysics. The model used in this study is shown in the Fig. 1. The bath was $140 \mathrm{~mm}$ high. Diameters on the bottom and the top was 140 and $180 \mathrm{~mm}$. The diameter of the cylindrical ultrasonic horn was $20 \mathrm{~mm}, 30 \mathrm{~mm}$ and $40 \mathrm{~mm}$. The merging depth of the horn was $20 \mathrm{~mm}$. Cylindrical sapphire plates were placed beneath the horn. The diameter was $100 \mathrm{~mm}$, and the thickness was $20 \mathrm{~mm}$. Sound velocity of the liquid aluminum and sapphire was as $912 \mathrm{~m} / \mathrm{s}$ and $10835 \mathrm{~m} / \mathrm{s}$, and the density of them was $2.7 \mathrm{~kg} / \mathrm{cm}^{3}$ and $4 \mathrm{~kg} / \mathrm{cm}^{3}$. Since the 3D model can require a large amount of calculation, and it is actually axisymmetric, an 2D model was used to replace the 3D model.

The input power of the ultrasonic horn was set as $200 \mathrm{w}, 500 \mathrm{w}$ and $800 \mathrm{w}$. Distance between the horn and the sapphire was set as $10 \mathrm{~mm}, 20 \mathrm{~mm}$ and $30 \mathrm{~mm}$. The vibration frequency was $15 \mathrm{KHz}$.

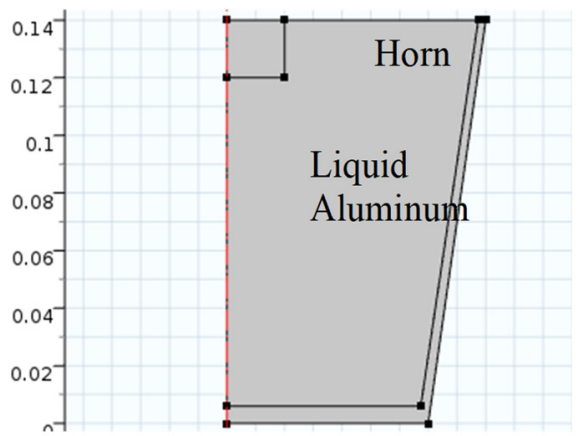

a)

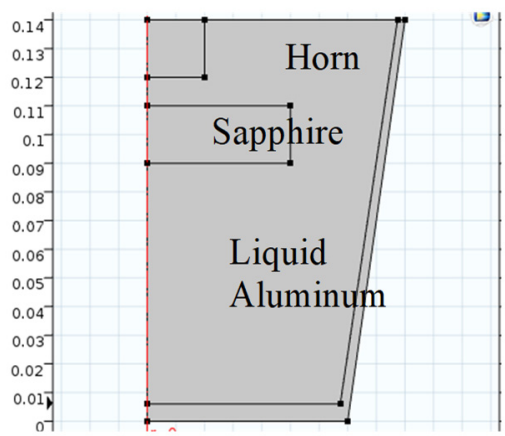

b)

Fig. 1. Model of the FEM: a) a bath with a ultrasonic horn,

b) a bath with a ultrasonic horn and a sapphire block

\section{Results and discussions}

The effects of the ultrasonic horn and the input power is shown in the Fig. 2. The nine figures in the Fig. 2 corresponds to nine situations, i.e. the diameter of ultrasonic horn was 20,30 and $40 \mathrm{~mm}$ and the input power was $200 \mathrm{w}, 500 \mathrm{w}$ and $800 \mathrm{w}$.

When the diameter was $20 \mathrm{~mm}$, the maximum sound pressure increased from $326 \mathrm{kPa}$ to $1.03 \mathrm{MPa}$ as the power increased from $200 \mathrm{w}$ to $800 \mathrm{w}$. The high vibration density area located near the horn.

When the diameter was $30 \mathrm{~mm}$, the maximum sound pressure increased from $500 \mathrm{kPa}$ to $1.47 \mathrm{MPa}$ as the power increased from $200 \mathrm{w}$ to $800 \mathrm{w}$. The high vibration density area located near the horn. It is noticeable that, as the diameter of the horn increased, the same power was scattered on a larger area, and it may theoretically decrease the maximum pressure. However, the maximum pressure increased and the high-density area expanded and reached a deeper place.

When the diameter was $40 \mathrm{~mm}$, the maximum sound pressure increased from $677 \mathrm{kPa}$ to $1.72 \mathrm{MPa}$ as the power increased from $200 \mathrm{w}$ to $800 \mathrm{w}$. The maximum pressure and high-density area expanded further comparing to situations. Thus, it is clear that the maximum sound pressure is not only decided by the ultrasonic power, but also decided by the size of the horn. This phenomenon is out of our expectation. The reason for this counterintuitive result may come from the coupling of the solid/liquid interface.

It is clear that when the power increased, both the maximum pressure and the high-density area increased significantly. Thus, a bigger horn with higher output power shall be more favorable in the ultrasonic treating.

The effects of the distance between the ultrasonic horn and the sapphire plate is shown in the Fig. 3, where the ultrasonic horn diameter was $40 \mathrm{~mm}$ and the input power was $800 \mathrm{w}$. 


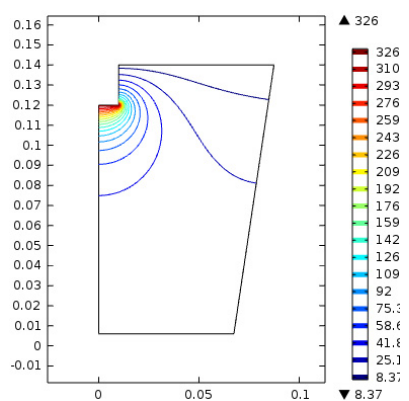

a)

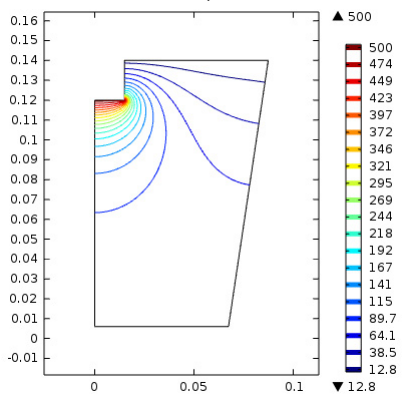

d)

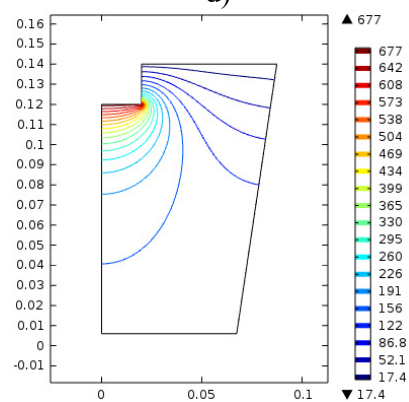

g)

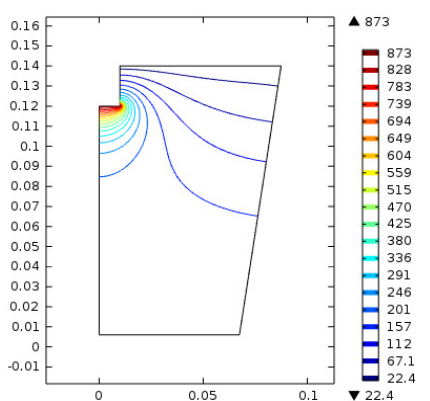

b)

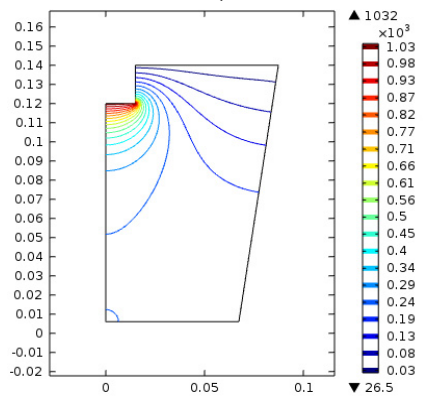

e)

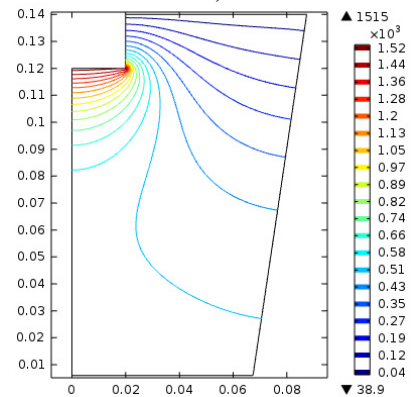

h)

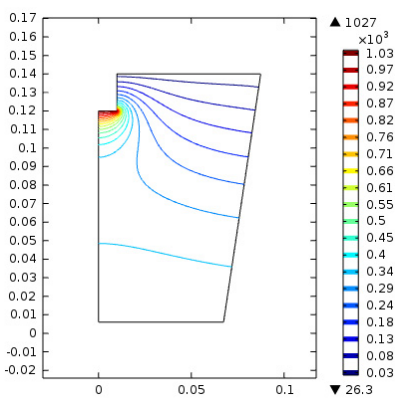

c)

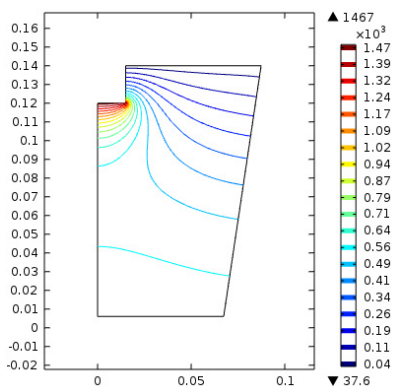

f)

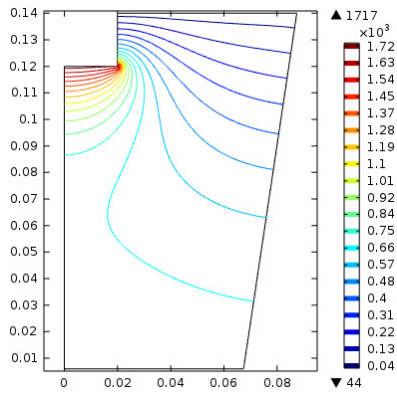

i)

Fig. 2. Ultrasonic vibration when the ultrasonic horn diameter and input power were: a) $20 \mathrm{~mm}, 200 \mathrm{w}$, b) $20 \mathrm{~mm}, 500 \mathrm{w}$, c) $20 \mathrm{~mm}, 800 \mathrm{w}$, d) $30 \mathrm{~mm}, 200 \mathrm{w}$, e) $30 \mathrm{~mm}, 500 \mathrm{w}$,

f) $30 \mathrm{~mm}, 800 \mathrm{w}, \mathrm{g}) 40 \mathrm{~mm}, 200 \mathrm{w}$, h) $40 \mathrm{~mm}, 500 \mathrm{w}$, i) $40 \mathrm{~mm}, 800 \mathrm{w}$

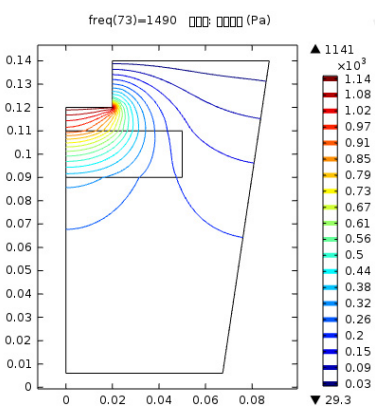

a)

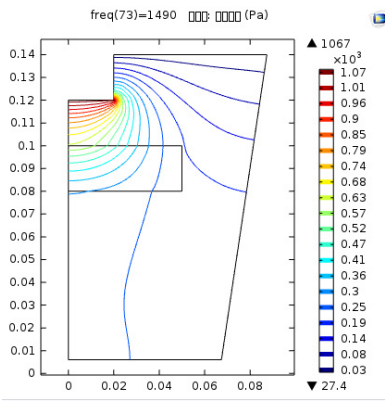

b)

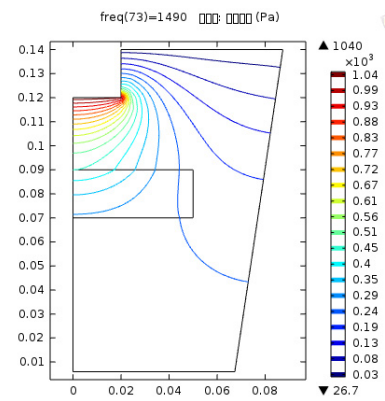

c)

Fig. 3. Ultrasonic vibration distribution when the distance between the ultrasonic horn and sapphire was: a) $10 \mathrm{~mm}$; b) $20 \mathrm{~mm}$, c) $30 \mathrm{~mm}$

The maximum ultrasonic pressure when the distance between the horn and the sapphire plate was $10 \mathrm{~mm}, 20 \mathrm{~mm}$ and $30 \mathrm{~mm}$ was $1.14 \mathrm{kPa}, 1.07 \mathrm{kPa}$ and $1.04 \mathrm{kPa}$. Comparing to the result in 
Fig. 2(i), the maximum pressure decreased significantly in these three conditions. This may result from the existence of sapphire plate disturbed the normal distribution of vibration. Moreover, the further is the sapphire plate from the horn, the more significantly the maximum pressure was decreased. And lastly, the contour lines in the figures showed a significant curve at the sapphire/liquid interface, which indicates a significant energy absorption there. Contour lines with higher values was affected more significantly, while those with lower values were merely slightly changed. This indicated that high-energy vibration was absorbed more than low energy vibration at the interface.

In all the three conditions, vibration density in the sapphire plate center was higher than that on the edge. The further the sapphire was from the horn, the lower the maximum pressure and the pressure grads on the surface were. Therefore, it is reasonable to state that, for an ultrasonic treatment procedure, it is essential to select proper distance according to the aim. If a fast treatment on a selected area is desired, short distance between the sapphire and the horn shall be selected. Otherwise, if an even treatment on the whole surface is needed, the sapphire plate shall be placed further to the horn.

\section{Conclusions}

FEM is used to analyze the distribution of ultrasonic vibration in a sapphire treatment procedure, and the following conclusion can be drawn:

1) Shape of the ultrasonic horn significantly affects the ultrasonic vibration.

2) Existence of sapphire in the ultrasonic treatment bath can significantly reduce the vibration density on general.

3) The vibration energy can be significantly absorbed at the liquid/sapphire interface. And high-energy vibration can be absorbed more significantly.

4) Vibration energy grads can be formed on sapphire surface. And this phenomenon shall be used to achieve different aims.

\section{Acknowledgements}

This research is sponsored by the Natural Science Foundation of Jiangsu Province (Nos. BK20160285 and BK20170320) and National Natural Science Foundation of China (Grant No. 51605141 and 51705039).

\section{References}

[1] Horng R. H. Thermal management and light extraction in multi-chip and high-voltage LEDs by cup-shaped copper heat spreader technology. Light-Emitting Diodes: Materials, Devices, and Applications for Solid State Lighting XVII, 2013, p. 86410R.

[2] de Pablos-Martin A., Ebert M., Patzig C., Krause M., Dyrba M. Laser welding of sapphire wafers using a thin-film fresnoite glass solder. Microsystem Technologies-Micro and Nanosystems-Information Storage and Processing Systems, Vol. 21, 2015, p. 1035-1045.

[3] Li Y., Liu S. Research on the soldering of sapphire optical filter used in infrared detector. Laser and Infrared, Vol. 44, 2014, p. 387-390.

[4] Gorbaty Y. E., Bondarenko G. V., Mileiko S. T. Soldered high-pressure high-temperature sapphire window. Review of Scientific Instruments, Vol. 65, Issue 8, 1994, p. 2739-2740.

[5] Ramirez A. G., Mavoori H., Jin S. H. Bonding nature of rare-earth-containing lead-free solders. Applied Physics Letters, Vol. 80, Issue 3, 2002, p. 398-400.

[6] Mavoori H., Ramirez A. G., Jin S. H. Universal solders for direct and powerful bonding on semiconductors, diamond, and optical materials. Applied Physics Letters, Vol. 78, Issue 19, 2001, p. 2976-2978.

[7] Cui W., Li S., Yan J., et al. Ultrasonic-assisted brazing of sapphire with high strength Al-4.5Cu-1.5Mg alloy. Ceramics International, Vol. 41, Issue 6, 2015, p. 8014-8022.

[8] Cui W., Yan J., Dai Y., et al. Building a nano-crystalline alpha-alumina layer at a liquid metal/sapphire interface by ultrasound. Ultrasonics Sonochemistry, Vol. 22, Issue 1, 2015, p. 108-112. 